\title{
Can Making of a Surgeon Be a Spiritual Pursuit?
}

\author{
Sukriti Rastogi ${ }^{1,2}$ (i) \\ Received: 25 December 2018 / Accepted: 27 December 2018/Published online: 7 January 2019 \\ (C) Association of Surgeons of India 2019
}

Sir,

We read with great interest the article by Chintamani et al. on "Can Making of a Surgeon be a Spiritual Pursuit?" [1]. This is the most unique article one may come across while searching for how a surgeon should ideally be trained.

The author has given a completely new dimension to our understanding of training in Surgery. One will agree that surgery can never be a simple mechanical job done with hands. It is always the job of a trained mind commanding their movements. It is said that, "the eyes cannot see what the mind does not know" and it holds utmost relevance in the field of Surgery.

The author has mentioned a brilliant analogy of a woodcutter to explain the correct training of mind and its result. This is like dancing which is not just steps performed in a sequential manner but flowing like water. It is the mind that is commanding the feet to be put at the right place, at the right time without much efforts to recall the next step. Similarly, one initially learns to play keyboard by looking at the keys but with right training one starts playing it with closed eyes. So, being spiritually involved can keep us moving in the "holy planes" that the author has mentioned.

In ancient times, surgical training meant devoting one's life to learn surgery as an art from the Guru. Even today, it has not changed much in that regard, and will never do. Surgery can only be learnt at the elbow of a mentor who raises consciousness, stimulates awareness, fosters creativity, and connects us with principal issues of purpose and meaning of this life. The

Sukriti Rastogi

sukriti.rastogi06@gmail.com

1 PGIMER \& Dr. RML Hospital, Baba Kharak Singh Marg, Near Gurudwara Bangla Sahib, Connaught Place, New Delhi 110001, India

2 New Delhi, India article stimulates us to re-educate ourselves regarding how we should be trained.

The author also subtly describes a complex entity; Spirituality in the article. Spirituality in training of a Surgeon refers to no more - and no less - a deep connection between the mentor, mentee, and the subject - a connection which is honest, vibrant, and relevant. Just holding the scalpel in hand by virtue of being a surgery resident does not make one a good surgeon. "A fool with a tool remains a fool." It is an inward journey that a mentor-mentee take together, to train the mind, learn and perform through new eyes.

Surgery is practice of wholeness and awareness. Spirituality is the meta-message of surgical training. One should not misunderstand this as preaching sentimental mush or as irrational, because surgical training can truly be a divine experience with each lesson taken as a mind- and soulexpanding trek. After entering surgical residency, one must stop and find relationship with the subject.

I recommend this article to every surgeon who is in making or in later part of the career as it brings out the essence of how Surgery should be learnt and taught the correct way.

\section{Compliance with Ethical Standards}

Conflict of Interest The author declares that he/she has no conflict of interest.

Publisher's Note Springer Nature remains neutral with regard to jurisdictional claims in published maps and institutional affiliations.

\section{Reference}

1. Chintamani (November 2015) Editorial: can making of a surgeon be a spiritual pursuit? Indian J Surgery (September-October 2015) 77(5):345-346 DOI https://doi.org/10.1007/s12262-015-1412-7 